\title{
A THERMODYNAMIC AND KINETIC BASIS FOR UNDERSTANDING CHROMIUM DEPLETION IN Ni-Cr-Fe ALLOYS
}

\author{
G. S. WAS and R. M. KRUGER \\ Department of Nuclear Engineering, The University of Michigan, Ann Arbor, MI 48109, U.S.A.
}

(Received 9 May 1984; in revised form 13 October 1984)

\begin{abstract}
Thermodynamic and kinetic models are constructed to describe the development of the chromium depleted zone in $\mathrm{Ni}-\mathrm{Cr}-\mathrm{Fe}$ alloys heated in the range $773-1173 \mathrm{~K}$. The models are interactive and constitute a computer program called DEPLETE. The thermodynamic model is constructed using the Kohler method for the description of the free energy of a multi-component system. It provides the chromium concentration at the carbide-matrix interface as a function of alloy composition and temperature. The kinetic model tracks the shape of the chromium profile as a function of time at temperature and grain size. Model results show that the interfacial chromium concentration decreases for increasing carbon concentration and decreasing heat treatment temperature. Experimental verification of the model is made using high resolution energy despersive X-ray analysis via STEM. Measured results agree well with model results for the dependence of chromium depletion on various input parameters as well as the magnitude and shape of the chromium depleted zone. Experimental measurements also show that the grain boundary carbides are of the form $M_{7} C_{3}$ where $M$ is about $96 \%$ chromium. Results confirm that carbide precipitation at the grain boundary is controlled by volume diffusion of chromium in the matrix and that in the temperature range 873 to $1073 \mathrm{~K}$ the chromium concentration in the grain boundary accurately approximates the carbide-matrix interfacial concentration.
\end{abstract}

Résumé-Nous construisons des modèles thermodynamique et cinétique pour décrire le développement de la zone dénudée en chrome dans un alliage $\mathrm{Ni}-\mathrm{Cr}-\mathrm{Fe}$ chauffé entre 773 et $1173 \mathrm{~K}$. Ces modèles interagissent et constituent un programme d'ordinateur appelé DEPLETE. Pour construire le modèle thermodynamique, nous utilisons la méthode de Kohler pour décrire l'énergie libre d'un système à plusieurs constituants. Ce modèle fournit la concentration en chrome à l'interface carbure-matrice en fonction de la composition de l'alliage et de la température. Le modèle cinétique concerne la forme du profil de chrome en fonction du temps pour une température et une taille de grains données. Les résultats de notre modèle montrent que la concentration interfaciale en chrome diminue lorsqu'on augmente la concentration de carbone et qu'on diminue la température de traitement thermique. Nous effectuons une vérification expérimentale du modèle par une analyse à haute résolution de dispersion en énergie de rayons $X$, à l'aide d'un MEBT. Les résultats expérimentaux sont en bon accord avec ceux du modèle en ce qui concerne tant la variation de la zone dénudée en chrome en fonction de divers paramètres, que la grandeur et la forme de cette zone. Les mesures expérimentales montrent également que les carbures intergranulaires sont de la forme $\mathrm{M}_{7} \mathrm{C}_{3}$, où $\mathrm{M}$ contient $96 \%$ de chrome environ. Nos résultats confirment que la précipitation de carbure intergranulaire est contrôlée par la diffusion volumique du chrome dans la matrice et qu'entre 873 et $1073 \mathrm{~K}$ la concentration de chrome intergranulaire est très proche de la concentration interfaciale carbure-matrice.

Zusammenfassung-Zur Beschreibung der Entwicklung einer an Chrom verarmten Zone in Ni-Cr-FeLegierungen bei Glühung im Temperaturbereich zwischen 773 und $1173 \mathrm{~K}$ werden thermodynamische und kinetische Modelle konstruiert. Die Modelle sind interaktiv und stellen ein Computerprogramm namens 'DEPLETE' dar. Das thermodynamische Modell wird unter Benützung der Kohler-Methode für die Beschreibung der freien Energie eines vielkomponentigen Systems konstruiert. Es liefert die Chromkonzentration an der Grenzfläche Karbid-Matrix in Abhängigkeit von der Legierungszusammensetzung und der Temperatur. Das kinetische Modell verfolgt die Form des Chromprofils in Abhängigkeit von der Zeit bei der jeweiligen Temperatur und von der Korngröße. Die Modellergebnisse zeigen, daß die Chromkonzentration an der Grenzfläche abnimmt, wenn die Kohlenstoffkonzentration ansteigt und die Glühtemperatur sinkt. Das Modell wird experimentell mittels hochauflösender Röntgenanalyse im Raster-Durchstrahlungselektronenmikroskop geprüft. Die Ergebnisse für die Abhängigkeit der Chromverarmung, die Breite und die Form der Verarmungszone stimmen bei den verschiedenen experimentellen Parametern gut mit dem Modell überein. Das Experiment zeigt außerdem, daß die Karbide an den Korngrenzen die Struktur $\mathrm{M}_{7} \mathrm{C}_{3}$ aufweisen, mit $\mathrm{M}$ ungefähr $96 \%$ Chrom. Diese Ergebnisse belegen, da $\beta$ die Karbidausscheidung an Korngrenzen durch die Volumdiffusion von Chrom in der Matrix gesteuert wird, und daß Chromkonzentration in der Korngrenze im Temperaturbereich zwischen 873 bis $1073 \mathrm{~K}$ genau der Konzentration in der Grenzfläche Karbid-Matrix entspricht. 


\section{INTRODUCTION}

For over 15 years, investigators have been developing models of the chromium depletion process in austenitic stainless steel during thermal treatment in the temperature range $773-1173 \mathrm{~K}[1,2]$. The motivation is clear. The loss of chromium in a region adjacent to the grain boundary in these alloys can lead to severe intergranular attack in aqueous environments $[3,4]$. To possess the capability of describing the redistribution of major alloying elements in the vicinity of the grain boundary without continually resorting to laboratory analysis would be an extremely powerful tool. When calibrated against data on intergranular attack, the model not only would become useful in diagnosing potential problems in service components but in preventing them and acting as an alloy design tool to obviate them.

Such a model could also be used to better understand and interpret intergranular corrosion test results. A knowledge of the interrelationships of the major and minor alloying elements would permit an evaluation of the effect of an added impurity (e.g. phosphorus or sulfur) on grain boundary chemistry and subsequent intergranular corrosion and stress corrosion cracking.

However, all models developed to date $[1,2]$ have relied upon the results of bulk corrosion experiments to test the validity of the predictions of chromium depleted zone depth, width and shape. Furthermore, only models for austenitic stainless steel have been developed and the important class of Ni-base alloys, including such technologically important alloys as Inconel 600 , have been neglected. What is needed is experimental verification of the chromium-depleted region under the same conditions as those treated in the models. Only then can the validity and accuracy of the models be unambiguously established.

This paper describes an integrated thermodynamic and kinetic model for the redistribution of chromium near the grain boundary of a $\mathrm{Ni}-16 \mathrm{Cr}-9 \mathrm{Fe}$ alloy (typical of Inconel 600 ) during thermal treatment. Model results consist of a quantitative description of the chromium depleted zone adjacent to a grain boundary as a function of time at temperature, alloy composition and grain size. The results are compared with chromium depletion profiles measured by quantitative scanning transmission electron microscopy, STEM.

\section{THERMODYNAMIC MODEL}

\subsection{Assumptions}

The following model describes the complete space-time history of the chromium concentration in a sample of a specified composition and grain size, held at temperature for a given length of time. The model applies to a nickel-base alloy containing nominally $16 \mathrm{wt} \% \mathrm{Cr}$ and $9 \mathrm{wt} \% \mathrm{Fe}$ with carbon present in the range $0.01-0.1 \mathrm{wt} \%$. The alloy must be single phase with all alloying elements uniformly distributed prior to heat treating. The model is based on the following assumptions:

(1) The only carbide present is of the form $\mathrm{M}_{7} \mathrm{C}_{3}$.

(2) The metallic content of the carbide is $100 \%$ chromium.

(3) The carbide forms a continuous film of uniform thickness along the grain boundary.

(4) A condition of local equilibrium exists at the carbide-matrix interface.

(5) Since the diffusion coefficient of carbon is several orders of magnitude higher than that of chromium, there will at all times be a spatially uniform carbon activity.

(6) No account is taken of the moving interface between carbide and matrix.

(7) No attempt is made to account for carbide nucleation or incubation time.

(8) The alloy is treated as a quaternary system in $\mathrm{Ni}-\mathrm{Cr}-\mathrm{Fe}-\mathrm{C}$.

The $\mathrm{Ni}-\mathrm{Cr}-\mathrm{Fe}-\mathrm{C}$ system is described by the Kohler model [5] using only binary interaction parameters. According to this model, the free energy of the solution is given by

$$
\begin{aligned}
G^{\text {f.c.c. }}= & x_{1} G_{\mathrm{Cr}}^{\text {f.c.s. }}+x_{2} G_{\mathrm{Ni}}^{\text {f.c.c. }}+x_{3} G_{\mathrm{Fe}}^{\text {f.c.c. }}+x_{4} G_{\mathrm{C}}^{\text {f.c.e. }} \\
& +R T\left[x_{1} \ln x_{1}+x_{2} \ln x_{2}\right. \\
& \left.+x_{3} \ln x_{3}+x_{4} \ln x_{4}\right] \\
& +\frac{x_{1} x_{2}}{x_{1}+x_{2}}\left\{x_{1} \mathrm{ACRNI}+x_{2} \mathrm{ANICR}\right\} \\
& +\frac{x_{1} x_{3}}{x_{1}+x_{3}}\left\{x_{1} \mathrm{ACRFE}+x_{3} \mathrm{AFECR}\right\} \\
& +\frac{x_{1} x_{4}}{x_{1}+x_{4}}\left\{x_{1} \mathrm{ACRCC}+x_{4} \mathrm{ACCCR}\right\} \\
& +\frac{x_{2} x_{3}}{x_{2}+x_{3}}\left\{x_{2} \mathrm{ANIFE}+x_{3} \mathrm{AFENI}\right\} \\
& +\frac{x_{2} x_{4}}{x_{2}+x_{4}}\left\{x_{2} \mathrm{ANICC}+x_{4} \mathrm{ACCNI}\right\} \\
& +\frac{x_{3} x_{4}}{x_{3}+x_{4}}\left\{x_{3} \mathrm{AFECC}+x_{4} \mathrm{ACCFE}\right\}
\end{aligned}
$$

where

$G_{j}^{\text {f.c.c. }}$ is the free energy of the pure component in the f.c.c. structure relative to its reference state in $\mathrm{cal} / \mathrm{mol}$,

AXXXX are the binary interaction parameters given in Table 1

and $\mathrm{Cr}=x_{1}, \mathrm{Ni}=x_{2}, \mathrm{Fe}=X_{3}$, and $\mathrm{C}=x_{4}$, where the 
Table 1. Binary interaction parameters and $\Delta G_{c}^{\text {f.e.c. } \rightarrow \text { Gr }}, \Delta G_{C,}^{\text {f.c.c. b.c.c. }}$ in $\mathrm{cal} / \mathrm{mol}$

\begin{tabular}{|c|c|}
\hline & Reference \\
\hline $\begin{array}{l}\text { ACRNI }=-2000+1.1202 \times 10^{-3} T^{2}-1.8649 \times 10^{-6} T^{3} \\
\text { ACRFE }=1770-1.5 T \\
\text { ACRCC }=-52000\end{array}$ & $\begin{array}{l}15 \\
15 \\
16\end{array}$ \\
\hline $\begin{array}{l}\text { ANICR }=-6000+2.2651 \times 10^{-3} T^{2}-6.231 \times 10^{-7} T^{3} \\
\text { ANIFE }=-8320+5.8327 \times 10^{-3} T^{3}-2.4859 \times 10^{-6} T^{3} \\
\text { ANICC }=-1900+1.03 T\end{array}$ & $\begin{array}{l}15 \\
15 \\
15\end{array}$ \\
\hline $\begin{aligned} \text { AFECR } & =1770-1.5 T \\
\text { AFENI } & =500-9.1573 \times 10^{-4} T^{2}+3.9029 \times 10^{-7} T^{3} \\
\text { AFECC } & =-22600-0.7 T\end{aligned}$ & $\begin{array}{l}15 \\
15 \\
15\end{array}$ \\
\hline $\begin{aligned} \mathrm{ACCCR} & =-52000 \\
\mathrm{ACCNI} & =-2600+16.18 T \\
\mathrm{ACCFE} & =-37100+1.39 T\end{aligned}$ & $\begin{array}{l}16 \\
15 \\
15\end{array}$ \\
\hline 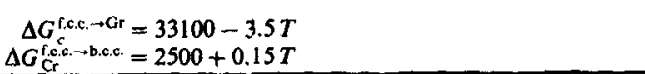 & $\begin{array}{l}14 \\
15 \\
\end{array}$ \\
\hline
\end{tabular}

$x_{i}$ are atom fractions in the f.c.c. phase, or generalized

$$
\begin{aligned}
G^{\text {f.c.c. }}=\sum_{i} x_{i} G_{i}+R T & \sum_{i} x_{i} \ln x_{i} \\
& +\sum_{i j} \frac{x_{i} x_{j}}{x_{i}+x_{j}}\left\{x_{i} g_{i j}+x_{j} h_{j i}\right\} .
\end{aligned}
$$

The partial molal free energy of the $i$ th component is given by

$$
\begin{aligned}
G_{i}= & R T \ln x_{i}+G_{i}+\sum_{i j} \frac{x_{i} x_{j}}{x_{i}+x_{j}}\left[\frac{x_{j}}{x_{i}+x_{j}}+1-x_{i}\right] g_{i j} \\
& +\sum_{i j} x_{i}\left[\left(\frac{x_{j}}{x_{i}+x_{j}}\right)^{2}-\frac{x_{i} x_{j}}{x_{i}+x_{j}}\right] h_{i j} \\
& -\sum_{j l}\left\{g_{i l}\left[\frac{x_{j}^{2} x_{i}}{x_{j}+x_{l}}\right]+g_{i j}\left[\frac{x_{i}^{2} x_{j}}{x_{j}+x_{l}}\right]\right\}
\end{aligned}
$$

and

$$
i \neq j ; i \neq l ; j \neq l \text {. }
$$

In particular, for chromium and carbon we have

$$
\begin{aligned}
\bar{G}_{C r}^{\text {f.c. }}= & G_{C_{r}}^{\text {f.c.c. }}+R T \ln x_{1} \\
& +\frac{x_{1} x_{2}}{x_{1}+x_{2}}\left\{\frac{x_{2}}{x_{1}+x_{2}}+1-x_{1}\right\} \text { ACRNI } \\
& +x_{2}\left\{\left(\frac{x_{2}}{x_{1}+x_{2}}\right)^{2}-\frac{x_{2} x_{1}}{x_{1}+x_{2}}\right\} \text { ANICR } \\
& +\frac{x_{1} x_{3}}{x_{1}+x_{3}}\left\{\frac{x_{3}}{x_{1}+x_{3}}+1-x_{1}\right\} \text { ACRFE } \\
& +x_{3}\left\{\left(\frac{x_{3}}{x_{1}+x_{3}}\right)^{2}-\frac{x_{3} x_{1}}{x_{1}+x_{3}}\right\} \text { AFECR } \\
& +\frac{x_{1} x_{4}}{x_{1}+x_{4}}\left\{\frac{x_{4}}{x_{1}+x_{4}}+1-x_{1}\right\} \text { ACRCC } \\
& +x_{4}\left\{\left(\frac{x_{4}}{x_{1}+x_{4}}\right)^{2}-\frac{x_{4} x_{1}}{x_{1}+x_{4}}\right\} \text { ACCCR } \\
& -\frac{x_{2}^{2} x_{3}}{x_{2}+x_{3}} \text { ANIFE }-\frac{x_{3}^{2} x_{2}}{x_{2}+x_{3}} \text { AFENI } \\
& -\frac{x_{2}^{2} x_{4}}{x_{2}+x_{4}} \text { ANICC }-\frac{x_{4}^{2} x_{2}}{x_{2}+x_{4}} \text { ACCNI } \\
& -\frac{x_{3}^{2} x_{4}}{x_{3}+x_{4}} \text { AFECC }-\frac{x_{4}^{2} x_{3}}{x_{3}+x_{4}} \text { ACCFE }
\end{aligned}
$$

and

$$
\begin{aligned}
\bar{G}_{C .}^{\text {f.c.c. }}= & G_{\mathrm{C}}^{\text {f.c. }}+R T \ln x_{4} \\
& +\frac{x_{4} x_{1}}{x_{4}+x_{1}}\left\{\frac{x_{1}}{x_{4}+x_{1}}+1-x_{4}\right\} \text { ACCCR } \\
& +x_{1}\left\{\left(\frac{x_{1}}{x_{1}+x_{4}}\right)^{2}-\frac{x_{1} x_{4}}{x_{1}+x_{4}}\right\} \text { ACRCC } \\
& +\frac{x_{4} x_{2}}{x_{4}+x_{2}}\left\{\frac{x_{2}}{x_{4}+x_{2}}+1-x_{4}\right\} \text { ACCNI } \\
& +x_{2}\left\{\left(\frac{x_{2}}{x_{2}+x_{4}}\right)^{2}-\frac{x_{2} x_{4}}{x_{2}+x_{4}}\right\} \text { ANICC } \\
& +\frac{x_{4} x_{3}}{x_{4}+x_{3}}\left\{\frac{x_{3}}{x_{4}+x_{3}}+1-x_{4}\right\} \text { ACCFE } \\
& +x_{3}\left\{\left(\frac{x_{3}}{x_{3}+x_{4}}\right)^{2}-\frac{x_{3} x_{4}}{x_{3}+x_{4}}\right\} \text { AFECC } \\
& -\frac{x_{1}^{2} x_{2}}{x_{1}+x_{2}} \text { ACRNI }-\frac{x_{2}^{2} x_{1}}{x_{1}+x_{2}} \text { ANICR } \\
& -\frac{x_{1}^{2} x_{3}}{x_{1}+x_{3}} \text { ACRFE }-\frac{x_{3}^{2} x_{1}}{x_{1}+x_{3}} \text { AFECR } \\
& -\frac{x_{2}^{2} x_{3}}{x_{2}+x_{3}} \text { ANIFE }-\frac{x_{3}^{2} x_{2}}{x_{2}+x_{3}} \text { AFENI }
\end{aligned}
$$

The condition of local equilibrium at the carbidematrix interface is given by

$$
K=\frac{a_{\mathrm{Cr}, C_{3}}}{\left(a_{\mathrm{Cr}}\right)^{7}\left(a_{\mathrm{C}}\right)^{3}}
$$

where $K$ is the equilibrium constant and $a_{\mathrm{Cr}_{7} \mathrm{C}_{3}}$ is the activity of the carbide which is taken to be unity. The equilibrium constant, $K$, is defined as

$$
\Delta G_{\mathrm{Cr}_{7} \mathrm{C}_{3}}^{\mathrm{r}}=-R T \ln K
$$

where $\Delta G_{\mathrm{Cr}_{7} \mathrm{C}_{3}}^{o}$ is the Gibbs free energy of formation of $\mathrm{Cr}_{7} \mathrm{C}_{3}$. Figure 1 shows the variation in $\Delta G_{\mathrm{Cr}_{7} \mathrm{C}_{3}}^{\mathrm{r}}$ with temperature between 600 and $1800 \mathrm{~K}$ as given by several investigators. The dashed lines represent extrapolations beyond the temperature range in which experiments were conducted. The data of Chase et al. [12] (curve No. 12) are used in this study. 


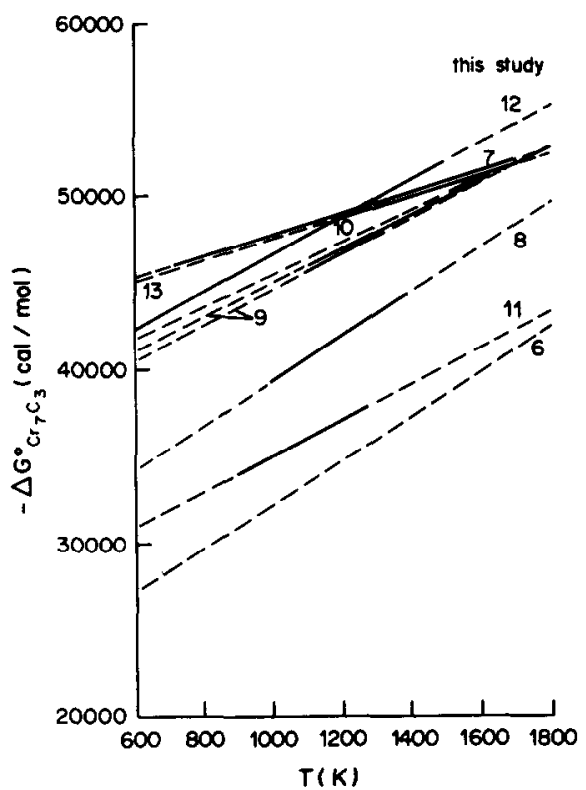

Fig. 1. Temperature dependence of Gibbs free energy of formation of the carbide $\mathrm{Cr}_{7} \mathrm{C}_{3}$. Numbers refer to the references.

In addition, since the carbide is taken to be composed solely of chromium and carbon, the ratio of nickel to iron is everywhere constant

$$
x_{2} / x_{3}=\text { constant }
$$

and

$$
x_{1}+x_{2}+x_{3}+x_{4}=1 .
$$

\subsection{Solution procedure}

The objective is to solve for the chromium and carbon concentrations at the carbide-matrix interface. As a first step, equations (4) and (5) are rewritten as

$$
R T \ln a_{\mathrm{Cr}}=G_{\mathrm{Cr}_{\mathrm{r}}}^{\text {f.c. }}+R T \ln x_{1}+\text { etc } \ldots,
$$

and

$$
R T \ln a_{\mathrm{C}}=G_{\mathrm{C}}^{\text {f.c.c. }}+R T \ln x_{4}+\text { etc.... }
$$

Equations (4a), (5a), (6), (8) and (9) comprise a system of 5 equations in 5 unknowns, $x_{1}, x_{2}, x_{3}, x_{4}$ and $a_{\mathrm{cr}}$. Recall that $a_{\mathrm{c}}$ is known from the matrix concentration.

The solution procedure is as follows:

(1) $a_{\mathrm{C}}$ is calculated from equation (5a) given the matrix composition.

(2) $a_{\mathrm{Cr}}$ is calculated from equation (6) and (7). This is the value of the chromium activity at the carbidematrix interface.

(3) Equations (4a), (5a), (8) and (9) are then solved simultaneously for the concentrations of the alloying elements at the interface. In practice, $x_{2}$ and $x_{3}$ are eliminated from equations (4a) and (5a) using equations (8) and (9) resulting in a system of two nonlinear equations in two unknowns, $x_{1}$ and $x_{4}$.

(4) A completely discretized Newton-Raphson method is used to solve for the chromium and carbon levels.

\subsection{Model verification}

The thermodynamic model is checked on an alloy of composition 73.69 at. $\%$ Ni-16.74 at.\% $\mathrm{Cr}-9.42$ at. $\% \mathrm{Fe}-0.153$ at. $\% \mathrm{C}$ held at $973 \mathrm{~K}$, Table 2 . This composition is similar to Inconel 600 heat NX8698 produced by Huntington Alloys Inc. Since the thermodynamic model only accounts for major alloying elements and equation (9) must be satisfied, all minor alloying elements and impurities are incorporated into the nickel concentration while the chromium and iron contents remain unaltered. Results are given in Fig. 2.

For the nominal alloy composition $\left(x_{\mathrm{C}}=0.00153\right.$ at. fr.), the concentrations of chromium and carbon in paraequilibrium with the carbide are given as $x_{\mathrm{Cr}}^{i}=0.12$ at. fr. and $x_{\mathrm{C}}^{i}=7.1 \times 10^{-4}$ at. fr. This level of chromium is considerably higher than the 0.06 0.08 at. fr. levels measured previously using STEM [17]. During the course of the thermal treatment, carbon is progessively consumed by the formation and growth of the $\mathrm{Cr}_{7} \mathrm{C}_{3}$ carbide layer. Since the carbon in the matrix is modeled as remaining spatially uniform during this process, the carbon level will drop throughout the grain. This drop in $x_{\mathrm{C}}^{\gamma}$ causes a corresponding drop in $x_{\mathrm{C}}^{i}$ and an increase in $x_{\mathrm{Cr}}^{i}$ until the carbon level reaches the solubility limit. The time progression of this process can be simulated by performing calculations for decreasing levels of $x_{\mathrm{C}}^{\gamma}$ in the alloy which represents a movement from right to left along the abscissa in Fig. 2. Using this simulation, $x_{\mathrm{C}}^{y}$ should equal $x_{\mathrm{C}}^{i}$ at the solubility limit as designated by the $X$ on the $45^{\circ}$ line, and $x_{\mathrm{C}_{r}}^{\gamma}$ should equal $x_{\mathrm{Cr}}^{i}$. However, $x_{\mathrm{C}}^{i}>x_{\mathrm{C}}^{y}$ and $x_{\mathrm{Cr}_{\mathrm{r}}}^{i}>x_{\mathrm{C}_{\mathrm{r}}}^{\nu}$. This disagreement indicates one of two things; that the use of binary interaction terms alone is insufficient to

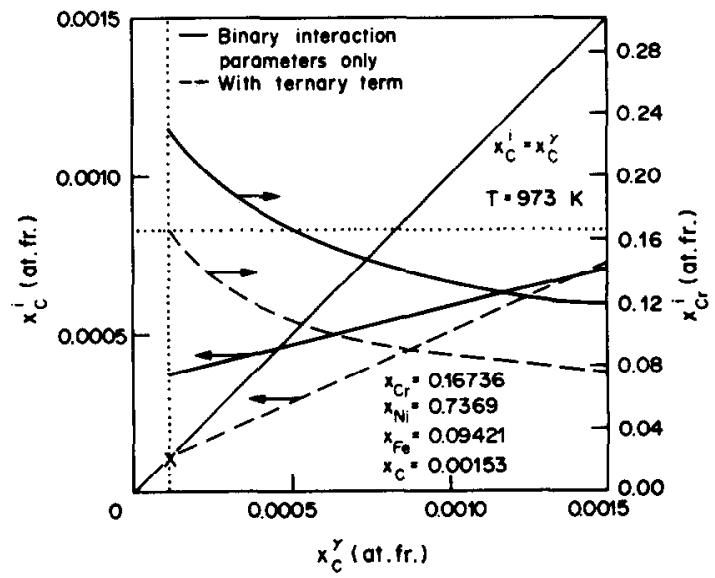

Fig. 2. Paraequilibrium concentrations of carbon and chromium at the carbide-matrix interface at $973 \mathrm{~K}$ for the binary parameter model. 
accurately model the thermodynamics of $\mathrm{Cr}_{7} \mathrm{C}_{3}$ precipitation in this alloy, or that the values of the binary interaction parameters are inaccurate. Since no conflicting data exists and we have no solid foundation for altering the values of these parameters, the former argument will be accepted.

Further support is lent to this argument by considering the magnitude of the carbon activity coefficient. The calculated activity coefficient of carbon in the matrix at $973 \mathrm{~K}$ is about 26. Bradley et al. [18] have shown substantial differences between the calculated coefficient and experimental measurements of carbon in a $\mathrm{Fe}-\mathrm{Ni}-\mathrm{C}$ alloy at $1273 \mathrm{~K}$. Their measurements show that the carbon activity coefficient is about 130 in an alloy containing $80 \% \mathrm{Ni}$ while the activity coefficient calculated using only binary interaction parameters gives a value of about 50 . The addition of ternary interaction parameters produces a good fit between experimental and calculated values.

To completely characterize a quaternary system one needs, in addition to the binary terms, ternary and quaternary terms. However, the use of such an extensive description of this system is pointless unless the thermodynamic data exists to permit assignment of values to these terms. Because of the lack of experimental data and tabulated ternary interaction parameters for this system, a single ternary interaction parameter will be introduced. Following the Kohler method [19], the quaternary system will be approximated as a ternary system of $\mathrm{Cr}+(\mathrm{Ni}+\mathrm{Fe})$ $+\mathrm{C}$. The additional term in the expression for the free energy of the system is

$$
\Delta G^{\mathrm{term}}=x_{1} x_{2} x_{4} A T
$$

where

$$
\begin{aligned}
& x_{1}=\mathrm{Cr} \\
& x_{2}=\mathrm{Ni}+\mathrm{Fe} \\
& x_{4}=\mathrm{C}
\end{aligned}
$$

and

$$
\begin{aligned}
A T= & \text { the temperature dependent ternary inter- } \\
& \text { action parameter in } \mathrm{cal} / \mathrm{mol} \text {. }
\end{aligned}
$$

Since a single ternary term is used to describe a quaternary system, the components $x_{2}$ and $x_{3}$ are lumped together and are treated as a single component. Therefore, the partial molal free energies corresponding to those in equation (10) are

$$
\bar{G}_{1}=-x_{1} x_{2} x_{4} A T
$$

and

$$
\bar{G}_{4}=x_{1} x_{2}\left(1-x_{4}\right) A T .
$$

The parameter $A T$ becomes the sole parameter with which the total thermodynamic model can be calibrated. It is not, however, a free parameter but is determined using the solubility of carbon in $\mathrm{Ni}-\mathrm{Cr}-\mathrm{Fe}$ as follows. For a given temperature and alloy composition, the matrix carbon level, $x_{\mathrm{C}}^{\gamma}$, is set at the solubility limit. A value of $A T$ is selected and

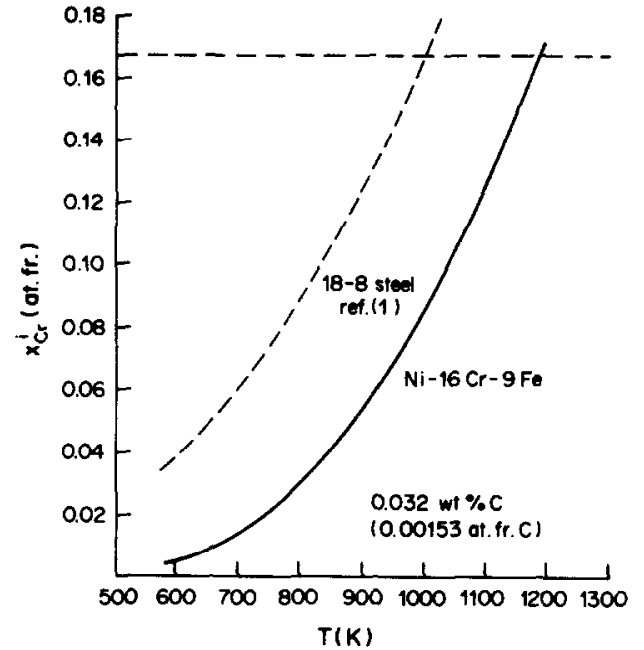

Fig. 3. Equilibrium chromium concentration at the carbide-matrix interface as a function of temperature.

$x_{C}^{i}$ and $x_{C r}^{i}$ are calculated using equations (4-6, 8 and 9) and compared with $x_{C}^{\gamma}$ and $x_{C r}^{\gamma}$ respectively. The value of $A T$ is iteratively adjusted until $x_{\mathrm{C}}^{\gamma}=x_{\mathrm{C}}^{i}$ and $x_{\mathrm{Cr}_{\mathrm{r}}}^{\gamma}=x_{\mathrm{C}_{\mathrm{r}}}^{i}$. If this process is carried out in the range $573 \mathrm{~K}$ to $1173 \mathrm{~K}, A T$ is determined to vary linearly with temperature (in $\mathrm{K}$ ) according to

$$
A T=-28.39 T+48258 \mathrm{cal} / \mathrm{mol} \text {. }
$$

This is based on solubility data taken from Ref. [20]

$$
\ln x_{C}=9.0-14713 / T
$$

where $x_{\mathrm{C}}$ is in $\mathrm{wt}^{\%} \%$ and $T$ is in $\mathrm{K}$.

The functional form of $A T$ given in equation (12) will be used for this study, and the paraequilibrium chromium concentration at the grain boundary as a function of temperature is given in Fig. 3. Note that for this alloy, the minimum grain boundary concentration of chromium is 7.55 at. $\%$ or about $6.8 \mathrm{wt} \%$. This agrees well with STEM results [17] of Cr levels in the range $6-8 \mathrm{wt} \% \mathrm{Cr}$ for short thermal treatment times at $973 \mathrm{~K}$. Further, the grain boundary $\mathrm{Cr}$ concentration reaches the solubility limit at $1180 \mathrm{~K}$ in agreement with solubility data. At low temperatures, the model predicts lower $\mathrm{Cr}$ concentrations, as expected. Thus, inclusion of a single term produces a match between the free energy expression and the solubility data, resulting in a thermodynamic model that produces interfacial concentrations of chromium and carbon that are in reasonable agreement with existing STEM data. Next, a kinetic model must be developed to describe the space-time evolution of the depleted zone.

\section{KINETIC MODEI}

Determination of the spatial profile of chromium at any time during thermal treatment requires solution of the time-dependent concentration equation

$$
\frac{\partial C}{\partial t}=D_{\mathrm{Cr}} \nabla_{r}^{2} x(r, t) \text {. }
$$


In the following model, equation (14) is discretized and solved numerically

$$
\begin{aligned}
V_{n} & \frac{x_{n}^{i}-x_{n}^{i-1}}{\Delta t} \\
& =-D_{\mathrm{Cr}}\left(A_{n} \frac{x_{n}^{i}-x_{n-1}^{i}}{\Delta r_{n-1}}-A_{n+1} \frac{x_{n+1}^{i}-x_{n}^{i}}{\Delta r_{n}}\right)
\end{aligned}
$$

where

$x_{j}^{i}=$ atom fraction of chromium at node $j$ and time $i$

$\Delta r_{j}=$ width of the $j$ th annulus

$A_{j}=$ surface area of the $j$ th shell

$V_{j}=$ volume of the $j$ th annulus

$D_{\mathrm{Cr}}=$ diffusion coefficient of $\mathrm{Cr}$ in $76 \mathrm{Ni}-15 \mathrm{Cr}-9 \mathrm{Fe}$ (from Ref. [21]),

$t=$ time increment.

\section{Rearranging gives}

$$
\begin{aligned}
\frac{-D A_{n} \Delta t}{V_{n} \Delta r_{n-1}} x_{n-1}^{i}+\{1 & \left.+\frac{D \Delta t}{V_{n}}\left(\frac{A_{n}}{\Delta r_{n-1}}+\frac{A_{n+1}}{\Delta r_{n}}\right)\right\} x_{n}^{\prime} \\
& -\frac{D A_{n+1} \Delta t}{V_{n} \Delta r_{n}} x_{n+1}^{i}=x_{n}^{i-1} .
\end{aligned}
$$

Note that the chromium concentration at the interface, $x_{\mathrm{Cr}}^{i}$, will be grain size dependent since

$$
h=\sum_{j=1}^{N} \Delta r_{j}
$$

For a sphere consisting of $N$ shells, we have $N$ equations in $N+2$ unknowns. The left side of each equation contains the $\mathrm{Cr}$ concentration for the present time step and the RHS is the $\mathrm{Cr}$ concentration at the previous time step. The system of equations is tridiagonal except for the first and last equations which contain one extra term each. The first term of the first equation is eliminated by setting $x_{0}=x_{1}$ since $J=0$ at the center of the sphere. The last term on the RHS of the last equation is eliminated by readjusting the right hand side of the last equation to include the $x_{n+1}$ term which is the interfacial chromium concentration for the current time step. The $N$ equations now form a tridiagonal matrix which is solved by a Crout reduction algorithm [22]. The solution of the kinetic model proceeds as follows.

At the beginning of a time step, the kinetic model receives, as input from the thermodynamic model, the chromium and carbon concentrations at the interface for the specified alloy composition and thermal treatment temperature. Next the matrix carbon level is decremented toward the solubility limit. Given the chromium diffusion coefficient, the interfacial chromium concentration, $x_{\mathrm{Cr}}^{l}$ and the chromium concentration at the last node, $x_{C_{r}}^{N}$, the time to diffuse a corresponding amount of chromium (equal to $7 / 3$ of the carbon increment) into the grain boundary is calculated according to

$$
t=D_{\mathrm{Cr}} \frac{\Delta x}{\Delta r}
$$

where

$$
\frac{\Delta x}{\Delta r}
$$

is defined as

$$
\frac{x_{\mathrm{Cr}}^{N}-x_{C r}^{i}}{r_{N}-r_{i}}
$$

Using this time and the chromium concentration profile from the previous time step, the set of $N$ equations is solved. The solution produces a new value of the chromium concentration at the last node, $x_{\mathrm{Cr}}^{N}$, which is then used with $D_{\mathrm{Cr}}$ and $x_{\mathrm{Cr}}^{i}$ to arrive at a new estimate of the time to diffuse the same amount of chromium into the grain boundary. This process is iterated until the change in time between successive iterations falls within a predetermined convergence limit. At this point, a new chromium profile is produced and the thermodynamic model produces a new value of $x_{C_{r}}^{i}$ and a new increment of carbon for the next time step.

It should be noted that the progression in time is really controlled by fixing the amount of carbon and chromium that flow to the carbide and solving for the time it takes to complete this process. This approach is followed because the precipitation process terminates not after a given amount of time, but when the matrix carbon level reaches the solubility limit. Since the flow rate is so strongly dependent on temperature, the time step size can vary by orders of magnitude and create real difficulty in developing a universal time stepping algorithm.

The only adjustable parameter in this model is the diffusion coefficient. It was determined by using the activation energy given by Pruthi et al. [21] for Inconel 600 and selecting the value of $D_{0}$ that best fit the data (presented in the following section) over a range of thermal treatment times at temperature. The value of $D_{0}$ found to best fit the data is 2.25 times that given by Pruthi. Results of the chromium depletion model follow.

\section{MODEL RESULTS}

The thermodynamic model describing the paraequilibrium level of chromium at the carbide-matrix interface as a function of alloy composition and temperature, and the kinetic model describing the time progression of the chromium profile near a grain boundary are combined into a single computer program. The program, DEPLETE, is written in BASIC for execution on an IBM personal computer. The reference conditions for all computed results are given in Table 2. To maintain consistency with the thermodynamic model, all results are based on the same alloy composition. This is denoted as the model development alloy in Table 2.

The time progression of the chromium profile for the model development alloy is given in Fig. 4. As expected, the grain boundary chromium concen- 
Table 2. Reference conditions for the study of chromium depletion

\begin{tabular}{|c|c|c|c|}
\hline & Model & $\begin{array}{l}\text { development } \\
\text { alloy }\end{array}$ & $\begin{array}{l}\text { Model verification } \\
\text { alloy }\end{array}$ \\
\hline Heat No.: & & NX8698 & AFR91 \\
\hline \multirow{4}{*}{$\begin{array}{l}\text { Composition: } \\
\text { (at.fr) }\end{array}$} & $\mathrm{Ni}:$ & 0.7379 & 0.73103 \\
\hline & Cr: & 0.16736 & 0.18038 \\
\hline & Fe: & 0.09421 & 0.08735 \\
\hline & $\mathrm{C}:$ & 0.00153 & 0.00124 \\
\hline Grain size: & & & \\
\hline
\end{tabular}

Thermal treatment: $1373 \mathrm{~K}$ for $20 \mathrm{~min}$ followed by $973 \mathrm{~K}$ for 1 to $100 \mathrm{~h}$.

tration rises and the width of the depleted zone widens with increasing time. Figure 5 shows the change in the shape of the depleted zone as a function of temperature after heat treating for $100 \mathrm{~h}$. As expected, for a given thermal treatment time, an increase in temperature causes an increase in $x_{\mathrm{Cr}}^{i}$ and the depleted zone width.

Figure 6 shows the effect of grain size on the chromium depletion profile after $100 \mathrm{~h}$ at $973 \mathrm{~K}$. A smaller grain size means a shorter diffusion path and a more rapid approach to true equilibrium. Thus for the same length of time, a smaller grain material will have a higher grain boundary concentration and consequently a flatter chromium profile at the grain boundary than the larger grain material. The effect of carbon content on $x_{\mathrm{Cr}}^{i}$ at time $t=0$ is shown in Fig. 7. Note that the paraequilibrium chromium concentration decreases with increasing carbon content and changes most rapidly at low values of carbon.

As a first step in benchmarking this model, a comparison will be made with the results of Stawström and Hillert [1] on stainless steel. There is a difference in base alloy composition and in the structure and composition of the chromium carbide between stainless steel and $\mathrm{Ni}-\mathrm{Cr}-\mathrm{Fe}$. However, since both processes occur in an austenitic structure, are diffusion-controlled and lead to formation of a chromium carbide at the grain boundary, they should

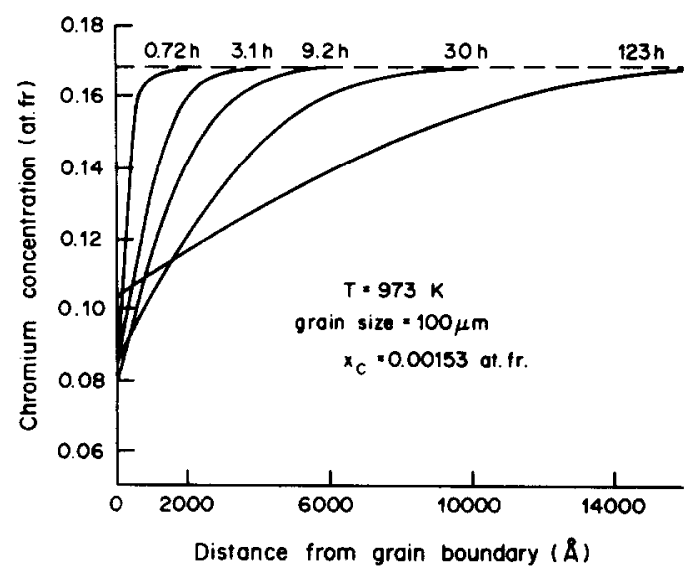

Fig. 4. Time progression of the chromium concentration profile for the reference conditions.

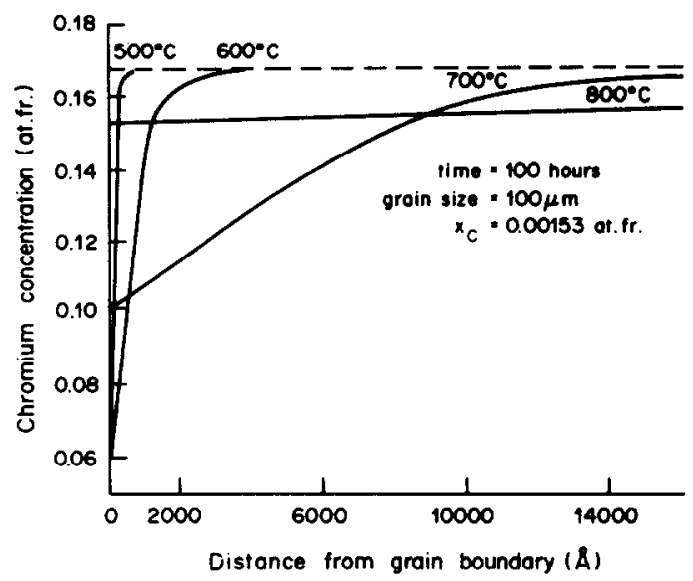

Fig. 5. Effect of temperature on the chromium concentration profile after $100 \mathrm{~h}$.

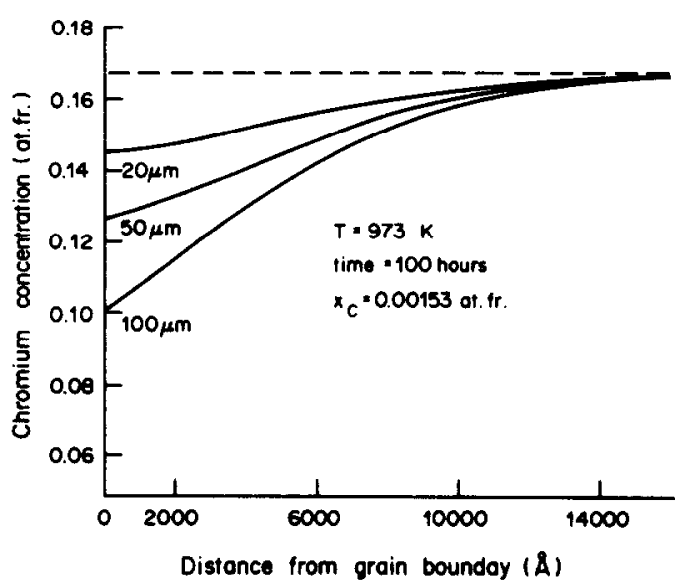

Fig. 6. Effect of grain size on the chromium concentration profile after $100 \mathrm{~h}$ at $973 \mathrm{~K}$.

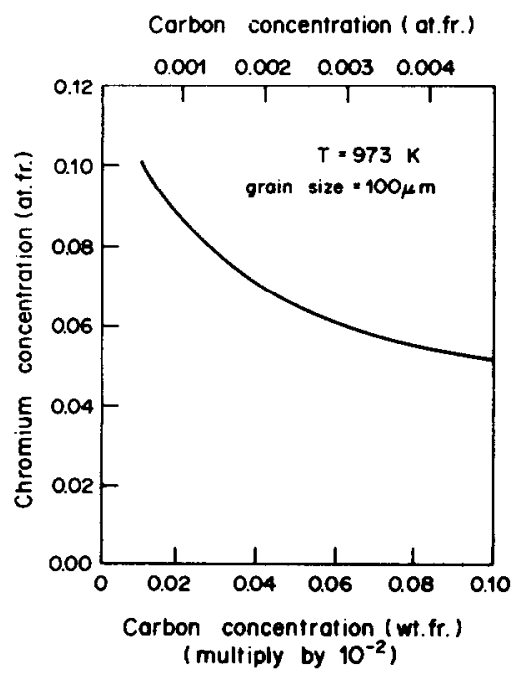

Fig. 7. Equilibrium chromium concentration at the carbide-matrix interface as a function of alloy carbon content. 


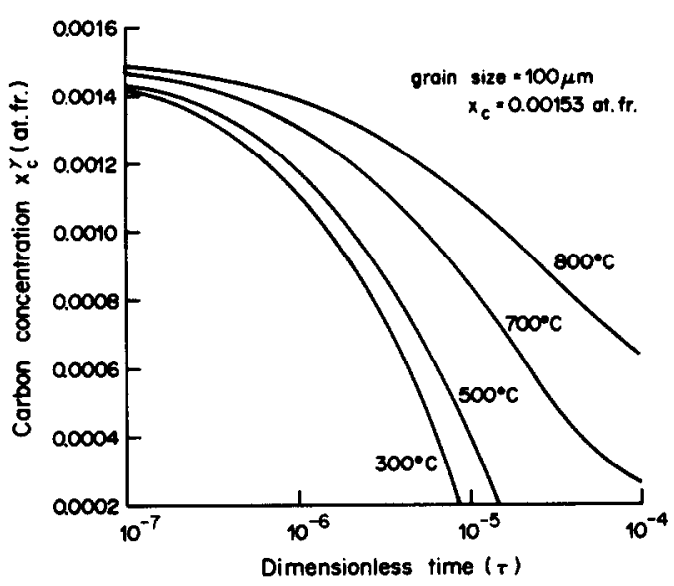

Fig. 8. Carbon content in the matrix as a function of time at temperature.

exhibit similar trends and dependencies even though the magnitudes may differ.

Figures 8-10 show the concentration of carbon remaining in the austenite matrix, the carbon activity and the chromium concentration at the carbidematrix interface, respectively, all as a function of the dimensionless time parameter, $\tau$, defined by

$$
\tau=D t / h^{2}
$$

where $h=$ grain size. Comparing these results with those for stainless steel (Figs 5-7 in Ref. [1]) it is noted that the curves have the same shape and display the same dependencies. In particular, an intersection of all the curves in the plots of carbon activity vs $\tau$ (Fig. 9) occurs for both $\mathrm{Ni}-\mathrm{Cr}-\mathrm{Fe}$ and stainless steel but at different values of $\tau$ and $a_{C}$. Referring to Fig. 3, the equilibrium interfacial chromium concentration is plotted as a function of temperature for both $\mathrm{Ni}-\mathrm{Cr}-\mathrm{Fe}$ (solid line) and stainless

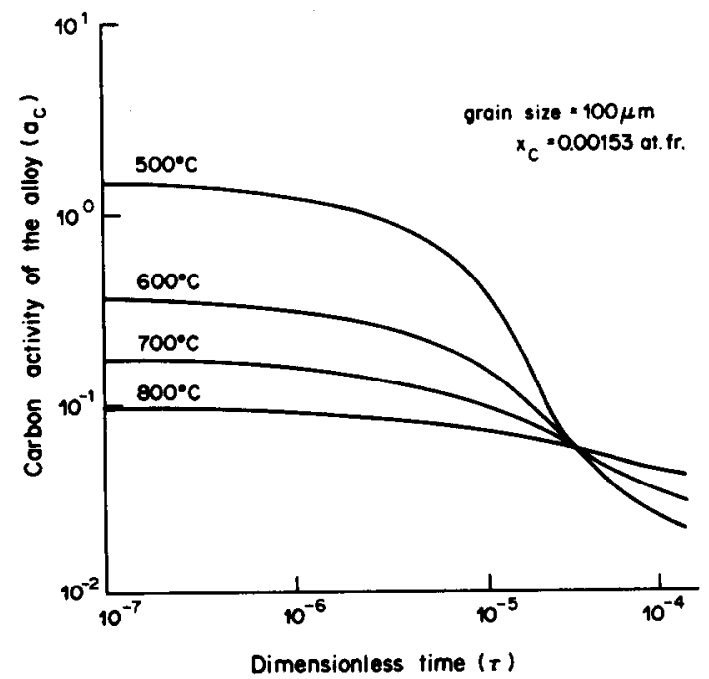

Fig. 9. Carbon activity of the alloy as a function of time at temperature.

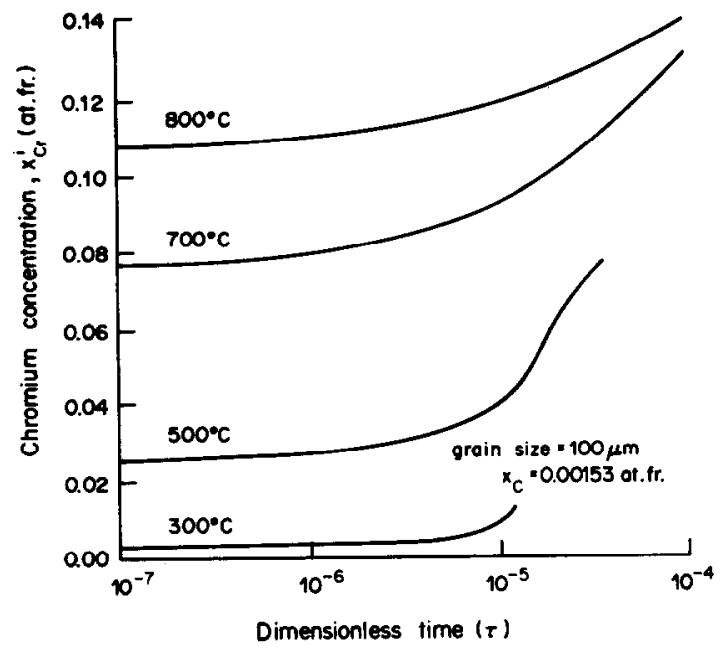

Fig. 10. Chromium concentration at the carbide-matrix interface as a function of time and temperature.

steel (dashed line). This shows that for an equivalent carbon concentration, the minimum $\mathrm{Cr}$ level in $\mathrm{Ni}-\mathrm{Cr}-\mathrm{Fe}$ is considerably less than that for stainless steel. Finally, Fig. 11 shows a direct comparison of results for stainless steel [23] and $\mathrm{Ni}-\mathrm{Cr}-\mathrm{Fe}$ for the same grain size and thermal treatment temperature.

\section{EXPERIMENT}

As stated earlier, unambiguous confirmation of any physical model can only be made by direct measurement of the same quantity that the model predicts. In this case, that quantity is the magnitude

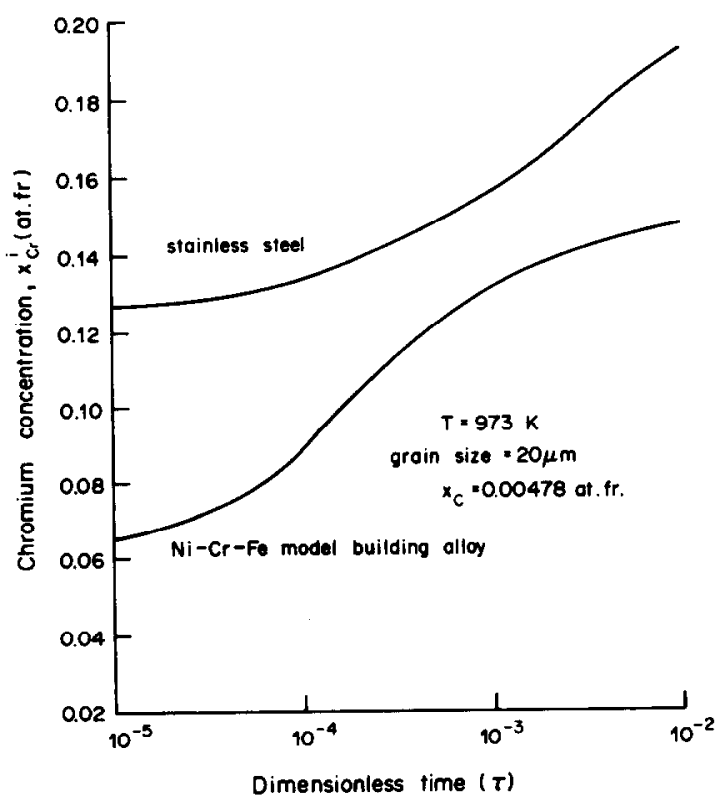

Fig. 11. Comparison of carbide-matrix interfacial chromium concentration for the $\mathrm{Ni}-\mathrm{Cr}-\mathrm{Fe}$ model building alloy and stainless steel. 
of the chromium depleted zone as a function of time at temperature, composition and grain size. A specially made heat, designated AFR91, was prepared for such experimental analysis. The alloy composition is given in the second column of Table 2 and is denoted the model verification alloy. The primary difference between this alloy and heat NX8698 is that AFR91 is an ultra-pure $\mathrm{Ni}-\mathrm{Cr}-\mathrm{Fe}$ alloy with a controlled carbon addition and maximum impurity content (of any single element) of $27 \mathrm{wppm}$. This alloy thus represents a true $\mathrm{Ni}-\mathrm{Cr}-\mathrm{Fe}-\mathrm{C}$ alloy and no approximations need be made.

Samples of heat AFR91 are thermally treated at $1373 \mathrm{~K}$ for $20 \mathrm{~min}$ to resolutionize any carbides that may have been present from the processing stage. The samples are then subjected to isothermal heat treatments at $973 \mathrm{~K}$ for $1,10,30$ and $100 \mathrm{~h}$ followed by a water quench. Samples are thinned for TEM analysis using a single jet electropolisher and a solution of $70 \%$ methanol, $20 \%$ ethylene glycol and $10 \%$ perchloric acid.

Chromium depletion profiles are obtained in a JEOL-100CX STEM fitted with an energy dispersive $X$-ray spectrometer. The local concentrations of major alloying elements are determined by stepping the electron beam in a direction perpendicular to and across the grain boundary in 250 to $2000 \AA$ increments. The electron beam trace is always performed midway between grain boundary carbides and through a gap at least $1000 \AA$ wide. $X$-ray counts are collected at each position for $100-200 \mathrm{~s}$ and the intensities are converted to concentrations using the Cliff-Lorimer equations [24].

Carbide crystal structure is determined by electron diffraction analysis of grain boundary carbides in an extraction replica. Metallographic samples are electroetched in a $70 \%$ methanol, $20 \%$ ethylene glycol, $10 \%$ perchloric acid solution at $253 \mathrm{~K}$ and $7-10 \mathrm{~V}$ for 1 s. The specimens are then carbon coated to a thickness of several hundred angstroms, and are electropolished a second time using the same solution under the same conditions and until the film can be removed with a grid. After sufficient etching, the samples are removed to a beaker of methanol and the films are floated onto aluminium grids for analysis. All electron diffraction experiments are performed at $100 \mathrm{kV}$.

The composition of the carbides is determined by $x$-ray analysis of carbides in the replica. However, only a ratio of intensities of the major elements is used.

\section{RESULTS}

Electron diffraction analysis of grain boundary carbides confirms that after thermal treatment at $973 \mathrm{~K}$ for 1 and $30 \mathrm{~h}$, the crystal structure is $\mathrm{M}_{7} \mathrm{C}_{3}$. This structure is hexagonal with 80 atoms per unit cell and is distinguished by its "streaky" electron diffraction pattern caused by faults in the crystal structure [25]. Thus, assumption No. 1 in the thermodynamic model is substantiated.

Since no standards are available, the relative abundance of major alloying elements in the carbides is determined by ratioing the $\mathrm{X}$-ray intensities. However, since the only elements present are $\mathrm{Ni}, \mathrm{Cr}, \mathrm{Fe}$ and $\mathrm{C}$, both absorption and fluoresence corrections should be small $[26,27]$ and these data should be a good indication of relative concentration. The data show that, except for thermal treatment times less than $1 \mathrm{~h}$, the ratio of $\mathrm{X}$-ray intensities for chromium $\left(I_{\mathrm{Cr}}\right)$ to the total $\left(I_{\mathrm{Ni}}+I_{\mathrm{Cr}}+I_{\mathrm{Fe}}\right)$ is approximately $96 \%$ with $0<I_{\mathrm{Fe}} / I_{\text {total }}<2 \%$ and $0<I_{\mathrm{Ni}} / I_{\text {total }}<2 \%$. Since these data are taken from carbides embedded in the extraction replica, the X-ray spectrum from the adjacent carbon film was subtracted out from the total count. Nevertheless, since some matrix material may remain attached to the carbide, these values are only approximate. However, the high percentage of chromium supports assumption No. 2 that the carbide is nearly all chromium.

In determining the local chromium concentrations in the matrix, the $\mathbf{X}$-ray intensities are converted to elemental concentrations at each point in the trace across a grain boundary. However, the concentration at the grain boundary is overestimated because of the finite probe size and its broadening through the foil. That is, since the chromium concentration is a minimum at the grain boundary and increases sharply with distance perpendicular to the boundary, the collected $\mathrm{X}$-rays may originate from a region near the boundary but with a significantly higher chromium concentration. Therefore, a correction is employed at the grain boundary to account for this signal contamination.

The electron probe size in our JEOL-100CX is measured at $100 \AA$ at the sample surface. In passing through the sample, broadening of the electron beam occurs due to scattering collisions between the incident electrons and the atoms comprising the sample. The total probe size is given as the sum of these two components

$$
b=b_{0}+6.25 \times 10^{-5} Z / E_{0}(\rho / A)^{1 / 2} t^{3 / 2} \mathrm{~cm}
$$

where $b_{0}$ is the initial probe size and the second term, developed by Goldstein [27], represents broadening by a simple single scattering model, $Z$ is the atomic number, $A$ is the atomic weight, $E_{0}$ is the electron energy in $\mathrm{eV}, \rho$ is the density in $\mathrm{g} / \mathrm{cm}^{3}$ and $t$ is the sample thickness in $\mathrm{cm}$. For a nominal sample thickness of $1000 \AA$, the broadening is about $200 \AA$ (for a $\mathrm{Ni}-16 \mathrm{Cr}-9 \mathrm{Fe}$ alloy) yielding a total probe size of about $300 \AA$.

Given the chromium concentration at a point adjacent to the grain boundary ( $\sim 500 \AA$ away) and asuming that the chromium concentration varies linearly from the grain boundary to $A$, the adjacent 
analysis point $\dagger$, then the concentration at any point $r$ between the grain boundary and $A$, is given by

$$
x(r)=x_{0}+r\left(x_{A}-x_{0}\right) / A
$$

where

$$
\begin{aligned}
x(r)= & \text { chromium concentration at point } r \\
x_{A}= & \text { chromium concentration at point } A \\
x_{0}= & \text { true grain boundary chromium concentration } \\
r= & \text { perpendicular distance from grain boundary } \\
A= & \text { distance from grain boundary to the next } \\
& \text { measurement. } \\
A= & \text { distance from grain boundary to the next } \\
& \text { measurement. }
\end{aligned}
$$

Since $x_{0}$ is the true grain boundary concentration and $x_{m}$ is the measured grain boundary concentration, the two quantities can be related through the following expression

$$
D x_{m}=2 \int_{0}^{D / 2} \mathrm{~d} r x(r)
$$

where

$$
x_{m}=\underset{\substack{\text { measured } \\ \text { concentration }}}{\text { grain boundary chromium }}
$$

and

$$
D=\text { total probe size. }
$$

Substituting the relation for $x(r)$ into equation (21) and solving for $x_{0}$ gives

$$
x_{0}=\frac{x_{m}-(D / 4 A) x_{A}}{1-D / 4 A} .
$$

Using a value of $300 \AA$ for $D$ and values of $A$ and $x_{A}$ measured at the adjacent point, one can arrive at the true value of the grain boundary concentration. Corrections for probe size range from 1 at. $\%$ for a steep chromium gradient (such as after $1 \mathrm{~h}$ at $973 \mathrm{~K}$ ) to 0 at. \% for a flat gradient (such as after $100 \mathrm{~h}$ at $973 \mathrm{~K})$.

A correction must also be made for grain boundary tilt. The correction to the measured grain boundary concentration is [28]

$$
\Delta x_{\mathrm{Cr}}^{i}=\left(\frac{\mathrm{d} \alpha}{4}+\frac{\tan ^{2} \theta H^{2} \alpha}{12 d}\right) \cos \theta
$$

where

$$
\begin{aligned}
\Delta x_{\mathrm{Cr}}^{i}= & \text { correction to measured grain boundary } \\
& \text { value in at. } \% \\
d= & \text { electron probe size in } \AA \\
\alpha= & \text { slope of chromium profile at the boundary } \\
& \text { in at. } \% / 10^{3} \AA \\
H= & \text { foil thickness in } \AA \\
\theta= & \text { grain boundary tilt angle in degrees. }
\end{aligned}
$$

$\lceil$ This is valid as long as the distance between the grain boundary and the adjacent analysis point is larger than the total beam diameter but small enough to avoid variation in the diffusion profile. A distance between $\mathbf{3 0 0}$ and $600 \AA$ is acceptable.

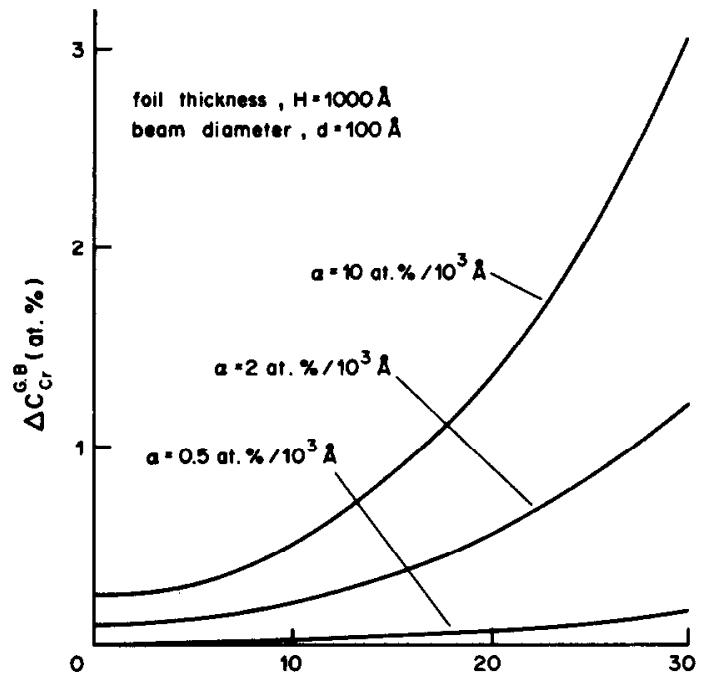

Grain boundary tilt ongle (degrees)

Fig. 12. The effect of beam broadening on the measured grain boundary chromium concentration as a function of the slope of the local chromium concentration profile.

Results are plotted in Fig. 12 for values of $\alpha$ ranging from 0.5 to 10 at. $\% / 10^{3} \AA$ for a $1000 \AA$ thick foil and an electron probe diameter of $100 \AA$. Note that for a steep chromium concentration profile, tilt angles greater than $20^{\circ}$ can result in substantial errors in measured grain boundary concentrations.

Using these procedures the experimentally determined grain boundary chromium concentration profiles for AFR91, annealed and thermally treated at $973 \mathrm{~K}$ for $1,10,30$ and $100 \mathrm{~h}$ are plotted in Figs 13-16 with error bars that represent a one sigma deviation about the mean value. The solid line is the calculated profile from DEPLETE. Notice that the calculated profile matches the experimental data extremely well in both the overall shape (a check on the accuracy of the kinetic model) and the grain boundary concentration (a check on the accuracy of the

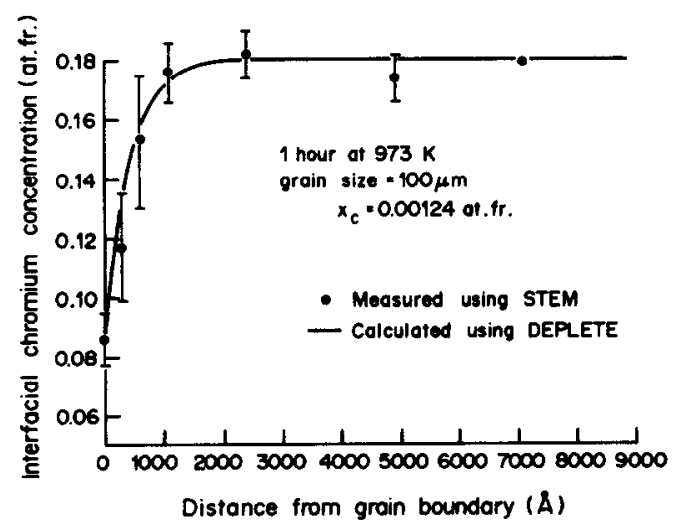

Fig. 13. Measured vs calculated interfacial chromium concentration for the model verification alloy held at $973 \mathrm{~K}$ for $1 \mathrm{~h}$. Each data point represents the average of about 10 measurements. 


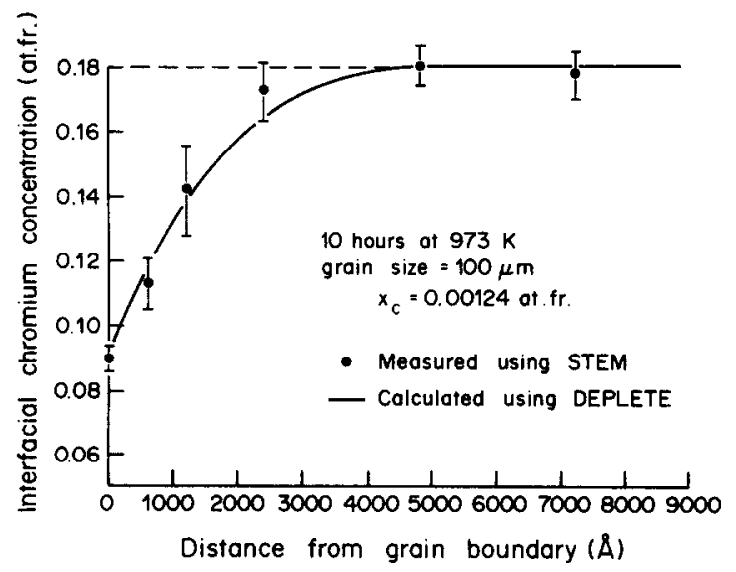

Fig. 14. Measured vs calculated interfacial chromium concentration for the model verification alloy held at $973 \mathrm{~K}$ for $10 \mathrm{~h}$. Each data point represents the average of about 8 measurements.

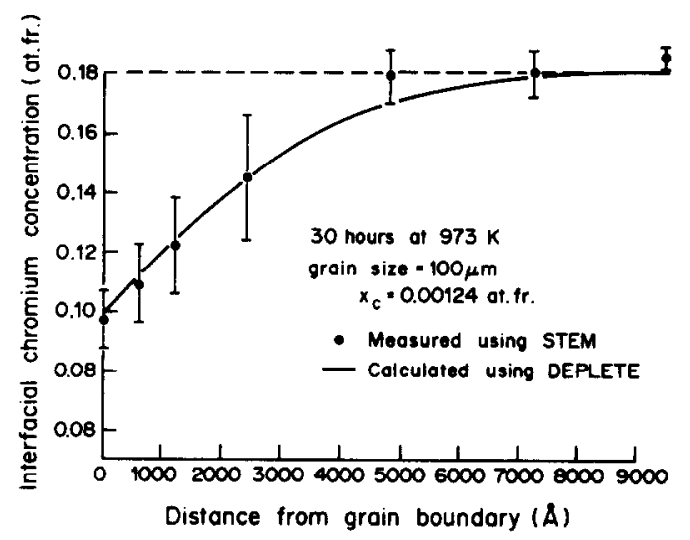

Fig. 15. Measured vs calculated interfacial chromium concentration for the model verification alloy held at $973 \mathrm{~K}$ for $30 \mathrm{~h}$. Each data point represents the average of about 5 measurements.

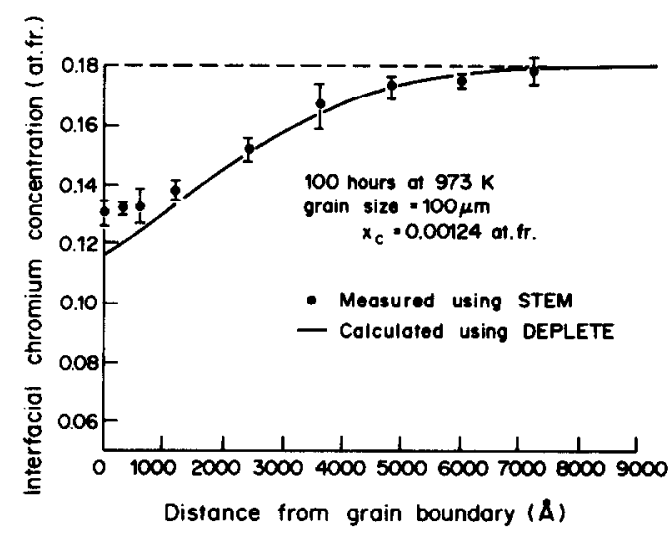

Fig. 16. Measured vs calculated interfacial chromium concentration for the model verification alloy held at $973 \mathrm{~K}$ for $100 \mathrm{~h}$. Each data point represents the average of about 4 measurements.

thermodynamic model) for the 1,10 and $30 \mathrm{~h}$ thermal treatments. The profile for the $100 \mathrm{~h}$ heat treatment, Fig. 16, however, deviates from the measured data up to a distance of $4000 \AA$ from the grain boundary. This can be explained (as discussed later) by the precip- itation of matrix carbides which are not accounted for in the thermodynamic model (assumption No. 3).

Figures 13-16 show the comparison of experimental measurements and model calculations for the development of the chromium depleted zone as a function of time at temperature. Figures 17 and 18 show the same comparison for heat treatments of $873 \mathrm{~K}$ for $250 \mathrm{~h}$ and $1073 \mathrm{~K}$ for $0.42 \mathrm{~h}$, respectively. The thermal treatment times were selected to result in chromium depleted zone widths comparable to that after $10 \mathrm{~h}$ at $973 \mathrm{~K}$, Fig. 14. The effects of differences in grain size $(100 \%$ increase) and carbon content (15\% decrease) are given in Table 3.

\section{DISCUSSION}

With two exceptions, results show that integrated thermodynamic and kinetic models can be developed to accurately describe the chromium depletion process in austenitic nickel-base alloys. Referring to Fig. 16, recall that a significant fraction of the carbides present after $100 \mathrm{~h}$ are intragranular carbides. Intragranular carbide precipitation removes

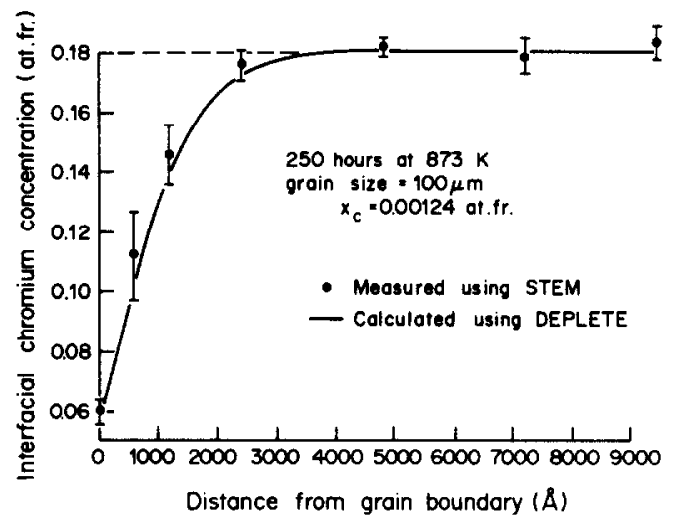

Fig. 17. Measured vs calculated interfacial chromium concentration for the model verification alloy held at $873 \mathrm{~K}$ for $250 \mathrm{~h}$. Each data point represents the average of about 5 measurements.

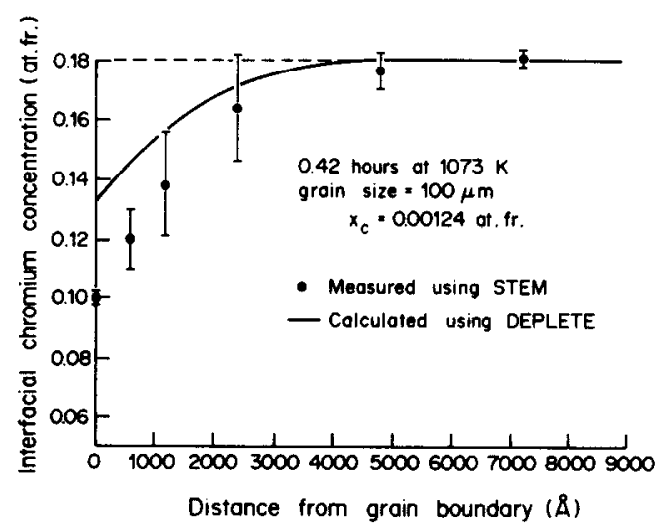

Fig. 18. Measured vs calculated interfacial chromium concentration for the model verification alloy held at $1073 \mathrm{~K}$ for $0.42 \mathrm{~h}$. Each data point represents the average of about 6 measurements. 
Table 3. Effect of alloy carbon content and grain size on the carbidemmatrix chromium concentration and the amount of carbon in solution after $100 \mathrm{~h}$ at $973 \mathrm{~K}$

\begin{tabular}{|c|c|c|c|c|c|c|c|}
\hline \multirow[b]{2}{*}{ Alloy } & \multirow[b]{2}{*}{$\begin{array}{c}\text { Carbon } \\
\text { content (at. \%) }\end{array}$} & \multirow[b]{2}{*}{$\begin{array}{c}\text { Grain } \\
\text { size }(\mu \mathrm{m})\end{array}$} & \multicolumn{2}{|c|}{$x_{\mathrm{Cr}}^{i}(\mathrm{at} \%)$} & \multicolumn{2}{|c|}{$x_{\mathrm{C}}(\mathrm{at} / \mathrm{p})$} & \multirow[b]{2}{*}{$\Delta x_{\mathrm{C}}^{\gamma}($ at. $\%)$} \\
\hline & & & Calculated & Measured & $\begin{array}{l}\text { Corresponding to } \\
\text { calculated } x_{\mathrm{Cr}}^{\prime}\end{array}$ & $\begin{array}{l}\text { Corresponding to } \\
\text { measured } x_{\mathrm{Cr}}^{i}\end{array}$ & \\
\hline AFR91 & 0.124 & 100 & 11.6 & 13.1 & 0.0445 & 0.0294 & 0.0151 \\
\hline AFR91 & 0.124 & $\underline{200}$ & 9.9 & 13.2 & 0.0780 & 0.0287 & 0.0493 \\
\hline AFR46 & 0.107 & 90 & 12.8 & 13.6 & 0.0309 & 0.0251 & 0.0058 \\
\hline
\end{tabular}

carbon from solution, lowering the carbon activity and increasing the interfacial chromium content, Fig. 2. This is reflected in the experimental data by the high measured grain boundary concentration of chromium relative to the model-calculated value. The model-calculated profile will agree with the experimental profile at a later time when grain boundary carbide growth has reduced the carbon activity to an equivalent level. In fact, the calculated grain boundary chromium concentration agrees with the measured concentration after $200 \mathrm{~h}$ at $973 \mathrm{~K}$. The amount of carbon removed from solution between 100 and $200 \mathrm{~h}$ is 0.0151 at. \%. Thus, only $12 \%$ of the carbon initially present need be taken up by intragranular carbides for measurement and calculation to agree. Hence, the formation and growth of intragranular carbides has the effect of accelerating the replenishment of the chromium depleted zone.

Table 3 illustrates that after long times at $973 \mathrm{~K}$, the discrepancy between calculated and measured grain boundary chromium concentration is due to the nucleation of intragranular carbides. Note that although the calculated value of $x_{C r}^{i}$ changes with grain size and carbon content, the measured values are all quite uniform. This can be explained by the amount of carbon remaining in solution. The 6 th and 7 th columns of Table 3 show the carbon calculated to be remaining in solution after $100 \mathrm{~h}$ at $973 \mathrm{~K}$, and after a time necessary for the calculated value of $x_{\mathrm{Cr}}^{i}$ to agree with the measured values, respectively. The difference in these values represents the amount of carbon taken up in intra granular carbides (last column). This variation is borne out quite dramatically by optical metallography which shows a high intragranular carbide density in the AFR91 alloy with $200 \mu \mathrm{m}$ grains, a low density in the AFR46 alloy and an intermediate density in the AFR91, $100 \mu \mathrm{m}$ sample.

The discrepancy between model and measured results at $1073 \mathrm{~K}$ is less readily explained. The most likely cause is the formation of a different phase, perhaps one that is richer in chromium. However, electron diffraction reveals only $\mathrm{Cr}_{7} \mathrm{C}_{3}$ carbides on the grain boundaries. Nevertheless, the experimental results are inconsistent with a model built on a carbon solubility curve. Inherent to these models is the prediction that grain boundary chromium levels should have a positive second derivative with temperature as in Fig. 3. Therefore, the possibility of undetected phases should not be ruled out.

One of the most interesting features of the model is the time-dependent nature of the carbide-matrix concentration of chromium which is responsible for some confusion about the shape of the depleted zone after thermal treatment at moderate temperatures for long times. Mulford et al. [29] noted this in stainless steel after $100 \mathrm{~h}$ at $973 \mathrm{~K}$ (the same treatment as given the sample shown in Fig. 16) and described the chromium profile as Gaussian. Henjered et al. [30] also noticed this in stainless steel after $8 \mathrm{~h}$ at $1023 \mathrm{~K}$ (which produces a depleted zone of the same width as a thermal treatment of $\sim 50 \mathrm{~h}$ at $973 \mathrm{~K}$ ), but was puzzled by the flat shape at the grain boundary.

The flattened profile near the grain boundary is indeed real and is a consequence of the timedependent interfacial chromium concentration. As precipitate growth proceeds, the matrix carbon content decreases causing a decrease in the carbon activity, an increase in the chromium activity (at the carbide-matrix interface) and an increase in the interfacial chromium concentration. The paraequilibrium chromium concentration at the carbidematrix interface soon rises above the chromium profile near the grain boundary causing a flattening at the grain boundary due to redistribution. This behavior is predicted by the model (Figs 4-6) and measured in practice (Fig. 16).

The process of chromium depletion and carbide growth modeled in DEPLETE accounts only for volume diffusion. Since grain boundary diffusion is ignored, the question arises concerning the suitability of using the chromium concentration measured at the grain boundary (and between carbides) to represent the carbide-matrix interfacial concentration. The following argument is proposed. The grain boundary diffusion coefficient for chromium is between 5 and 7 orders of magnitude greater than the volume diffusion coefficient at temperatures in the range 1073-873 K, respectively [21]. Hence, diffusion along the grain boundary is so fast that it is unlikely that a concentration gradient of measurable magnitude will be supported in a grain boundary when the average distance between carbides is less than $5000 \AA$. Pasparakis et al. [31] have shown that the shape of the concentration contours around a precipitate is a function solely of the homologous temperature. The lower the homologous temperature, the greater the ratio of flux contributed by grain boundary diffusion to that contributed by volume diffusion and the flatter the grain boundary concentration profile of the diffusant. In fact, for temperatures below approx. $0.7 T_{m}$ (1173 $\mathrm{K}$ for AFR91), this ratio asymptotically 
approaches infinity. Since the maximum temperature used in this study is $1073 \mathrm{~K}\left(0.64 T_{m}\right)$, we would expect grain boundary diffusion to strongly dominate the flux of solute to the particle and produce a flat solute concentration profile in the grain boundary. Hence, it is the strong domination of solute supply by grain boundary diffusion relative to volume diffusion that gives a flat profile in the grain boundary.

Measurements taken along grain boundary segments at 973 and $1073 \mathrm{~K}$ show no evidence of a chromium concentration profile in the boundary within the measurement limitations of this technique $( \pm 10 \%$ ). Although grain boundary diffusion is much faster than volume diffusion, it is the supply of solute to the grain boundary which is the rate limiting step Once at the grain boundary, it moves to the carbide so quickly that no concentration gradient develops. This is the reason why at these temperatures, measurements taken at the grain boundary (and between carbides) accurately approximate the carbide-matrix interfacial concentration.

Mention should also be made of efforts to model grain boundary diffusion to a growing carbide. This is an extremely difficult problem since it involves a description of a transient process that cannot be approximated by a steady state analysis. Perhaps the most complete analysis performed to date is by Rosolowski [32] who modeled the surface diffusion from a needle source and included the effect of volume diffusion into the bulk. However, this analysis neglects (1) the time-dependent boundary condition i.e. the concentration of chromium in paraequilibrium with the carbide (the carbide-matrix interfacial chromium concentration) increases with precipitation (time), (2) volume diffusion parallel to the grain boundary (which can be significant in the case of strong gradients in the grain boundary) and (3) the spherical geometry of the bulk (grain) which is significant for a grain size of $20 \mu \mathrm{m}$.

An analysis that includes these effects is extremely complicated, nearly intractable analytically and has not been attempted in this paper. Nevertheless, experimental evidence in combination with the earlier analysis shows that in these experiments, such a detailed treatment of grain boundary diffusion is not necessary to accurately describe the chromium depletion profiles.

Another point of interest is the implication of these results regarding low temperature sensitization (LTS). Inconel 600 is used in steam generator tubing in present day pressurized water reactors. Significant intergranular attack has occurred in numerous plants leading to plugging of tubes in most cases [33] and replacement of the entire steam generator in extreme cases [34]. Evidence of chromium depletion in these tubes has been found and concern over in-service sensitization at low temperatures $(573-623 \mathrm{~K})$ is mounting [35]. However, it is unlikely that a substantial chromium depleted zone can be formed at service temperatures.
Using the volume diffusion coefficient at $573 \mathrm{~K}$ and assuming volume diffusion to the grain boundary is rate-limiting, then the size of the depleted zone after 40 years is approx. $2(D t)^{1 / 2}$ or $3 \AA$. This figure is substantiated by calculations performed using DEPLETE. Even at $623 \mathrm{~K}$ the width of the depleted zone would only be $30 \AA$ and at $673 \mathrm{~K}$ it would be $230 \AA$. Thus unless another mechanism of diffusion is operative or severe macroscopic intergranular attack can occur with depleted zones of only a few lattice spacings in size, in-service chromium depletion of Inconel 600 in the temperature range $573-623 \mathrm{~K}$ should not be a problem in the life of the steam generator.

\section{CONCLUSIONS}

The chromium depletion code, DEPLETE, models the chromium concentration at the carbide-matrix interface as a function of alloy composition and temperature, and the chromium concentration profile into the matrix as a function of grain size and time at temperature.

The thermodynamic model uses binary interaction parameters and a single ternary interaction term with a temperature dependent coefficient determined from the carbon solubility data. Model results are extremely sensitive to the carbon solubility relation.

The development of the chromium depletion profile with time can be accurately modeled by considering only volume diffusion of chromium to the grain boundary.

With one exception, experimental results agree extremely well with model calculations. Although intragranular carbide precipitation causes measured and calculated results to deviate, the model is able to account for this deviation in a semi-quantitative fashion.

The only carbide detected at the grain boundary is of the form $\mathrm{M}_{7} \mathrm{C}_{3}$ where $\mathrm{M}=\mathrm{Cr}-2 \mathrm{at} \% \mathrm{Fe}-2 \mathrm{at} \%$ $\mathrm{Ni}$ except at short thermal treatment times when iron and nickel replace chromium.

- Experimental results show no measurable chromium gradient in the grain boundary, indicating that the grain boundary chromium concentration is probably a good indication of the chromium level at the carbide-matrix interface.

Acknowledgements - The authors gratefully acknowledge Professor Edward Hucke and Dr Larry Kaufman for their many stimulating and thought provoking discussions on the thermodynamic modeling, and the Electron Microbeam Laboratory for use of the facilities. This work was supported by the Office of Basic Energy Sciences of the U.S. Department of Energy under contract DE-AC02-82ER 13006.

\section{REFERENCES}

1. C. Stawström and M. Hillert, J. Iron Steel Inst., p. 77 (1969).

2. C. S. Tedmon Jr, D. A. Vermilyea and H. H. Rosolowski, J. Electrochem. Soc. 2, 192 (1971). 
3. R. L. Cowan II and C. S. Tedmon Jr, Advances in Corrosion Science, Vol. 3, 293, Plenum Press, New York (1973).

4. R. C. Scarberry, S. C. Pearman and J. R. Crum, Corrosion 32, 401 (1976).

5. F. Kohler, Monatsh. Chemie 91, 738 (1960).

6. M. Hillert, CALPHAD 1, 160 (1978).

7. V. Cihal and I. Kasova, Corr. Sci. 10, 875 (1975).

8. M. Waldenstrom and B. Uhrenius, Scand. J. Metal. 6, 202 (1977).

9. A. D. Kulkarni and W. L. Worrell, Metall. Trans. 3, 2362 (1972).

10. K. K. Kelley, U. S. Bureau of Mines, Bulletin No. 584 (1960).

11. M. Small and E. Ryba, Metall. Trans. 12A, 1389 (1981).

12. JANAF Thermochemical Tables, J. Phys. Chem. Ref. Data 4, 56 (1975).

13. R. D. Richardson, J. Iron Steel Inst., p. 33 (1953).

14. L. Kaufman and H. Nesor in Treatise on Solid State Chemistry (edited by N. B. Hanney), Vol. 5, No. 179, Plenum Press, New York (1975).

15. L. Kaufman and H. Nesor, CALPHAD 4, 295 (1978).

16. L. Kaufman, private communication, March (1983).

17. G. S. Was, H. H. Tischner and R. M. Latanision, Metall. Trans. 12A, 1397 (1981).

18. D. J. Bradley, R. O. Williams and F. H. Horne, CALPHAD 4, 265 (1980).

19. M. Hillert, CALPHAD 4, 1 (1980).

20. Technical service report, Solid Solubility of Carbon in Inconel Alloy 600, Huntington Alloy Products Division, Huntington, WV (1971).
21. D. D. Pruthi, M. S. Anand and R. P. Agarwala, J. Nucl. Mater. 64, 206 (1977).

22. F. B. Hildebrand, Methods of Applied Mathematics, 2nd edn. Prentice Hall, Englewood Cliffs, NJ (1965).

23. D. Sinigaglia, P. Fassina, D. Wenger and G. Re, Corrosion 38, 92 (1982).

24. G. Cliff and G. W. Lorimer, Proc. Fifth European Congress on Electron Microscopy, p. 140. Institute of Physics, Bristol (1972).

25. D. J. Dyson and K. W. Andrews, J. Iron Steel Inst., p. 208 (1969)

26. G. S. Was, ScD thesis, Massachusetts Institute of Technology, Cambridge, MA (1980).

27. J. J. Hren, J. I. Goldstein and D. C. Joy, Introduction to Analytical Electron Microscopy, p. 126. Plenum Press, New York (1979).

28. G. S. Was, Report No. UMNMP-10, Univ. of Michigan (1984).

29. R. A. Mulford, E. L. Hall and C. L. Briant, Corrosion 39, 132 (1983).

30. A. Henjered, H. Nordin, T. Thorvaldsson and H. O. Andrén, Scripta metall. 17, 1275 (1983).

31. A. Pasparakis, D. E. Coates and L. C. Brown, Acta metall. 21, 991 (1973).

32. J. H. Rosolowski, Metall. Trans. 3, 285 (1972).

33. C. Y. Cheng, Report No. NUREG-0886, Nuclear Regulatory Commission, Washington, DC (1982).

34. H. H. Woo and S. C. Lu, Lawrence Livermore Laboratory, UCRL-53032 (Sept. 1981).

35. E. Serra, Report No. NP-2114-SR, Electric Power Research Institute, Palo Alto, CA (1981). 